\title{
Parathyroid Hormonelike Protein from Human Renal Carcinoma Cells

\author{
Structural and Functional Homology with Parathyroid Hormone
}

\author{
Gordon J. Strewler, Paula H. Stern, John W. Jacobs, Jill Eveloff, Robert F. Klein, Steven C. Leung, \\ Michael Rosenblatt, and Robert A. Nissenson \\ Veterans Administration Medical Center and University of California, San Francisco, California 94121; the Department of \\ Pharmacology, Northwestern University Medical School, Chicago, Illinois 60611; and Merck Sharp and \\ Dohme Research Laboratories, West Point, Pennsylvania 19486
}

\begin{abstract}
A variety of solid tumors secrete proteins that are immunochemically distinct from parathyroid hormone (PTH) but activate PTH-responsive adenylate cyclase. Such PTH-like proteins have been proposed as mediators of the hypercalcemia and hypophosphatemia frequently associated with malignancies. We purified to apparent homogeneity a PTH-like protein with a molecular weight of 6,000 , that is produced by human renal carcinoma cells. The amino-terminal sequence of the PTH-like protein and that of human PTH were found to display at least five identities in the first 13 positions. The purified protein bound to PTH receptors, activated adenylate cyclase in renal plasma membranes, and stimulated cAMP formation in rat osteosarcoma cells. The PTH-like protein reproduced two additional effects of PTH, stimulation of bone resorption in fetal rat limb bone cultures and inhibition of phosphate uptake in cultured opossum kidney cells. These properties are consistent with a role for PTH-like proteins as mediators of the syndrome of malignancy-associated hypercalcemia.
\end{abstract}

\section{Introduction}

The possibility that malignant tumors could cause hypercalcemia by producing a substance resembling PTH was first suggested in 1941 by Albright, based on the coexistence of hypophosphatemia and hypercalcemia in a patient with renal carcinoma (1). It was subsequently noted that radioimmunoassays for PTH detected a cross-reacting substance in serum from patients with malignancy complicated by hypercalcemia (2). In most patients with squamous carcinomas or renal adenocarcinomas, hypercalcemia was characterized by a decreased renal phosphate threshold and by increased urinary excretion of nephrogenous cAMP, the PTH-dependent component of urinary cAMP (3).

Address reprint requests to Dr. Strewler, VA Medical Center (111N), 4150 Clement Street, San Francisco, CA 94121.

Received for publication 30 July 1987 and in revised form 11 September 1987.

The Journal of Clinical Investigation, Inc.

Volume 80, December 1987, 1803-1807
Recently, squamous and renal carcinomas have been shown to secrete proteins that, like PTH, activate adenylate cyclase in bone and kidney, yet are immunochemically distinct from PTH $(4,5)$. These proteins may also reproduce some of the physiological effects of PTH, as partially purified preparations have bone-resorbing $(6,7)$ and phosphaturic activity (8). Elaboration of PTH-like proteins by solid tumors is strongly correlated with development of hypercalcemia (6). These findings suggest a causative role of tumor-derived PTHlike proteins in hypercalcemia complicating solid tumors.

The human renal carcinoma cell line 786-0 was obtained from a hypercalcemic patient and produces hypercalcemia when grown as xenografts in the nude mouse (4). Here we report that a purified protein from 786- 0 cultures binds to high affinity PTH receptors in renal plasma membranes and mimics the physiologic effects of PTH in renal cells and bone explants. Homology between the amino-terminal sequence of the tumor protein and human PTH may account for their shared properties.

\section{Methods}

Purification. 4-d collections of medium containing $5 \mu \mathrm{M}$ leupeptin and $1 \mu \mathrm{M}$ pepstatin were obtained from confluent $786-0$ cells (clone $\mathrm{KEC}$ ), which were maintained as described (4). Conditioned medium (12-14 liter, stored at $-20^{\circ} \mathrm{C}$ ) was thawed and stirred for $2 \mathrm{~h}$ with $2.5 \mathrm{~g} / \mathrm{liter}$ controlled-pore glass beads (Sigma Chemical Co., St. Louis, MO). After beads were washed with $50 \%$ ethylene glycol, activity was eluted with $2 \mathrm{M}$ tetramethylammonium chloride. The eluate was dialyzed into $0.05 \mathrm{M}$ sodium acetate, $\mathrm{pH} 6.2$, and applied to a column of Sephadex CM-25, which was eluted with a linear gradient of 0-1 M $\mathrm{NaCl}$. Active fractions (eluting at $18-25 \mathrm{mMho}$ ) were made $0.1 \%$ in TFA $^{1}$ and applied to a $25 \mathrm{~cm} \times 4.6 \mathrm{~mm}$ HPLC column (Vydac 218 TP54; The Separations Group, Hesperia, CA); activity was eluted with a gradient (0-95\%) of $N$-propanol in $0.1 \%$ TFA at $0.16 \% \mathrm{~min}^{-1}$. Fractions with activity were lyophilized and redissolved in $0.1 \%$ TFA, then injected onto a $2.1 \mathrm{~cm} \times 4.6 \mathrm{~mm}$ HPLC column (Vydac 218TP52.1), which was developed with an N-propanol gradient (0-47.5\%) in $0.1 \%$ TFA at $0.079 \% \mathrm{~min}^{-1}$. Active fractions were lyophilized and incubated for $2 \mathrm{~h}$ at $37^{\circ} \mathrm{C}$ in $1 \%$ SDS, $10 \%$ glycerol, $0.0625 \mathrm{M}$ Tris, $\mathrm{pH} 6.8$. Gel electrophoresis was then carried out on a $9-26 \%$ polyacrylamide gra-

1. Abbreviations used in this paper: bPTH(1-34), bovine parathyroid hormone (1-34); Gpp(NH)p, 5'-guanylyl imidodiphosphate; $\mathrm{OK}$, opossum kidney; TFA, trifluoroacetic acid. 
dient in $0.1 \%$ SDS (9) with equine myoglobin and its cyanogen bromide fragments (Diversified Biotech, Newton Center, MA) as standards. Gel slices $(1 \mathrm{~mm})$ were eluted into $0.01 \mathrm{M}$ acetic acid containing 10\% (vol/vol) Extractagel D (Pierce Chemical Co., Rockford, IL).

PTH bioassays. PTH-like bioactivity was assayed as stimulation of cAMP formation in cultures of UMR-106 rat osteosarcoma cells (10) or stimulation of adenylate cyclase activity in canine renal plasma membranes (4). Results at serial dilutions were averaged, and are reported as the quantity of bPTH(1-34) required to produce an equivalent response.

Receptor binding assay. Binding of ${ }^{125} \mathrm{I}$-labeled PTH-like protein to the PTH receptor in canine renal plasma membranes was assayed as described for ${ }^{125} \mathrm{I}-\mathrm{bPTH}(1-34)$ (11), except that bound and free hormone were separated by microcentrifugation rather than filtration. When present, $\mathrm{Gpp}(\mathrm{NH}) \mathrm{p}$ was incubated with the reaction mixture for $25 \mathrm{~min}$ at $30^{\circ} \mathrm{C}$ before addition of labeled peptides. The PTH-like protein in $100 \mu \mathrm{l}$ of gel eluate was labeled with chloramine T (12). The labeled protein was separated from reactants by chromatography on Sephadex LH-20 as described (11), and purified by HPLC on a Vydac 218 TP52.1 column, using a $0-95 \%$ gradient of $N$-propanol in $0.1 \%$ TFA.

Bone-resorbing activity. Bone resorbing activity was determined as previously reported (13), as release of ${ }^{45} \mathrm{Ca}$ from prelabeled $19-\mathrm{d}$ fetal rat limb bones cultured for $72 \mathrm{~h}$ in Dulbecco's modified Eagle's medium supplemented with $15 \%$ heat-inactivated horse serum and 0.5 $\mu \mathrm{M}$ indomethacin.

Sodium-dependent phosphate uptake. Opossum kidney (OK) cells (clone 1G-9) were grown to confluence in 24 well plates (Costar, Hialeah, FL), as described (14). Cultures were transferred to $0.25 \mathrm{ml}$ of uptake medium (14) and incubated for $2 \mathrm{~h}$ at $37^{\circ} \mathrm{C}$ with test agents. Influx measurements were begun by addition of fresh uptake medium containing $0.1 \mathrm{mM}\left[{ }^{32} \mathrm{P}_{\mathrm{K}} \mathrm{HPO}_{4}(1 \mu \mathrm{Ci} /\right.$ well $)$. After $3 \mathrm{~min}$ at $37^{\circ} \mathrm{C}$, wells were rapidly washed thrice with $3 \mathrm{ml}$ of ice-cold wash solution (14). The monolayer was solubilized in $0.1 \%$ SDS for determination of phosphate uptake. Sodium-independent phosphate uptake, determined by replacement of $\mathrm{NaCl}$ in uptake medium by $137 \mathrm{mM} \mathrm{N}$ methyl-D-glucamine chloride, was subtracted from total uptake to calculate sodium-dependent uptake. Total and Na-independent phosphate uptake was linear for at least $5 \mathrm{~min}$.

Sequence determination. Polyacrylamide gels $(0.5$ or $0.75 \mathrm{~mm})$ were preelectrophoresed for $1 \mathrm{~h}$ with $0.5 \mathrm{mM}$ sodium thioglycolate in the upper reservoir; during electrophoresis the upper reservoir contained $0.1 \mathrm{mM}$ glutathione. Gel slices were eluted into $10 \mathrm{mM}$ acetic acid. Eluates with PTH-like activity were spotted on aminopropylsubstituted glass fiber filters, prepared as described (Applied Biosystems Protein Sequencer User Bulletin 25; Applied Biosystems, Foster City, CA), and electroeluted for $40 \mathrm{~min}$ at $30 \mathrm{~V}$ in $0.15 \mathrm{M} \mathrm{N}$-ethylmorpholine, $\mathrm{pH} 8.3$. Filters were soaked in polybrene $(60 \mathrm{mg} / \mathrm{ml})$ and dried. Automated Edman degradation was performed on an Applied Biosystems model 470A Protein Sequencer.

\section{Results}

Polypeptides with PTH-like bioactivity were purified from medium conditioned by 786-0 cells. The results in Table I are representative of three separate preparations. A 6,000-mol wt species (estimated by SDS gel electrophoresis) had $55-80 \%$ of the total PTH-like activity. Minor species (in descending order of abundance) had molecular weights of $\sim 3,400,8,000$, and 15,000 (data not shown). The small quantity of purified material precluded precise assessment of mass and hence specific activity. However, the purified 6,000 D component containing $2.4 \mu \mathrm{geq}$ of activity had $\sim 2 \mu \mathrm{g}$ protein by Coomassie Blue staining, giving an estimated specific activity of $1.2 \mathrm{mgeq}$ bPTH(1-34)/mg protein in the osteosarcoma cell bioassay.
Table I. Purification of PTH-like Protein

\begin{tabular}{lcccc}
\hline Step & Protein & Activity & $\begin{array}{l}\text { Specific } \\
\text { activity }\end{array}$ & Recovery \\
\hline & $m g$ & $\mu g e q$ & $\mu g e q / m g$ & $\%$ \\
& & $\begin{array}{c}\text { (osteosarcoma } \\
\text { assay) }\end{array}$ & & \\
Conditioned medium & 1360 & 42.6 & 0.031 & - \\
$\begin{array}{l}\text { 1. Controlled pore glass } \\
\text { 2. CM-Sephadex }\end{array}$ & 147 & 30.4 & 0.207 & 71.4 \\
3-4. HPLC $\times 2$ & 8.75 & 13.5 & 1.57 & 31.7 \\
5. SDS gel & 0.11 & 4.6 & 41.4 & 10.8 \\
$\quad$ electrophoresis & & & & \\
$\quad$ 6000 D & - & $2.3(0.10)^{*}$ & - & 5.4 \\
$\quad$ 3400 D & - & $0.93(0.06)$ & - & 2.2 \\
\hline
\end{tabular}

* Activity in renal adenylate cyclase assay.

The potencies, relative to bPTH(1-34), of the purified 6,000 D and 3,400 D forms were about 20 -fold lower in the renal adenylate cyclase assay than in the osteosarcoma cell assay. Similar potency differences were previously found using partially purified material (10). The 6,000 D species in gel eluates was further characterized, as described below.

It had previously been inferred that to activate adenylate cyclase, tumor-derived PTH-like proteins bind to the PTH receptor $(4,5)$. This issue was investigated in ligand-binding studies. Purified PTH-like protein retained bioactivity after iodination with chloramine $\mathrm{T}$ (data not shown). Labeled PTH-like protein bound to canine renal plasma membranes competitively with PTH (Fig. 1). Similar concentrations of unlabeled bPTH(1-34) $\left(\mathrm{EC}_{50}=0.1 \mathrm{nM}\right)$ were required to inhibit the binding of ${ }^{125} \mathrm{I}$-labeled PTH-like protein and ${ }^{125} \mathrm{I}-$ bPTH(1-34), suggesting that both labeled peptides occupied the same binding sites. Addition of $\mathrm{Gpp}(\mathrm{NH}) \mathrm{p}(0.1 \mathrm{mM})$ resulted in $96 \%$ inhibition of labeled PTH binding and $72 \%$ inhibition of binding of the labeled PTH-like protein.

The most prominent skeletal effect of PTH is activation of bone resorption. Table II shows that the PTH-like protein also had bone-resorbing activity. Although the experiments do not permit a precise assignment of potency, effects of $1 \mathrm{nM}$ PTH

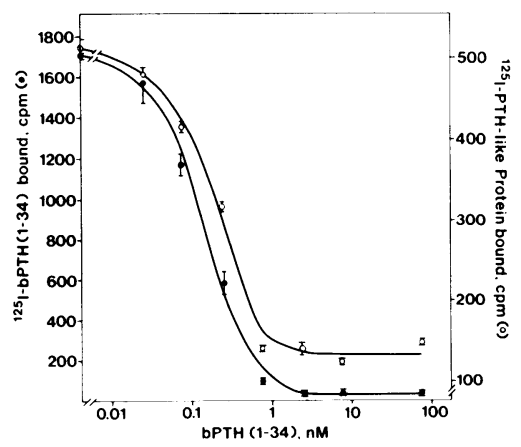

Figure 1. Competitive inhibition by $\mathrm{bPTH}(1-$ 34 ) of the binding of labeled PTH and labeled PTH-like protein to canine renal membranes. Added was $8300 \mathrm{cpm}$ ${ }^{125} \mathrm{I}$-bPTH(1-34) (•) and $6600 \mathrm{cpm}{ }^{125} \mathrm{I}$-labeled PTH-like protein (o). Binding in the absence of membranes was $11.3 \mathrm{cpm}$ for ${ }^{125} \mathrm{I}$ -

bPTH(1-34) and $90.8 \mathrm{cpm}$ for ${ }^{125}$ I-labeled PTH-like protein and was subtracted. Nonspecific binding was $<5 \%$ of total binding for ${ }^{125} \mathrm{I}$ bPTH(1-34) and was $25 \%$ of total binding for ${ }^{125}$ I-labeled PTH-like protein. Results are presented as mean \pm SEM of triplicate determinations from one experiment. The experiment was performed three times with similar results. 
Table II. PTH-like Protein has Bone-resorbing Activity

\begin{tabular}{lllll}
\hline & Addition & Concentration & ${ }^{45}$ Ca release & $P$ value* \\
\hline & & $n M$ or $n M e q$ & $\%$ & \\
& & & \\
Exp. 1 & None & & $17.6 \pm 1.0$ & \\
& bPTH (1-34) & 1.0 & $66.8 \pm 2.8$ & $<0.001$ \\
& PTH-like protein & $6.5(0.3)^{\ddagger}$ & $69.0 \pm 3.1$ & $<0.001$ \\
& Eluate control & & $22.4 \pm 4.3$ & NS \\
Exp. 2 & None & & $21.2 \pm 0.6$ & - \\
& bPTH (1-34) & 0.3 & $50.5 \pm 7.5$ & $<0.001$ \\
& & 1.0 & $70.1 \pm 5.3$ & $<0.001$ \\
& & 3.0 & $87.1 \pm 3.4$ & $<0.001$ \\
& PTH-like protein & $3.3(0.15)$ & $75.2 \pm 4.9$ & $<0.001$ \\
& & & &
\end{tabular}

Eluate control bones were incubated with a gel eluate from a lane with no sample. Values are mean \pm SEM of responses of four bones per point.

* Compared with no additions by ANOVA.

₹ Values in parentheses are concentrations based on potency in renal adenylate cyclase assay.

were equivalent to those of $3.3 \mathrm{nMeq}$ of the PTH-like protein $(0.15 \mathrm{nMeq}$ in the renal adenylate cyclase assay) suggesting that the potency of the PTH-like protein for bone resorption is intermediate between its potency in the other two assays.

To determine whether PTH-like protein also mimics the effect of PTH on renal phosphate transport, their effects on sodium-dependent phosphate uptake in OK cells were compared (Fig. 2). PTH induced a concentration-dependent inhibition of phosphate uptake. Preliminary experiments indicated that at $3 \mathrm{nM}$ PTH inhibition was maximal (data not shown). Purified PTH-like protein also induced a concentration-dependent decrease in phosphate uptake $(P<0.05$ by one-way ANOVA). The potency of PTH-like protein with respect to phosphate uptake was similar to its potency for activation of renal adenylate cyclase.

The amino-terminal sequence of PTH-like protein was determined by automated Edman degradation of two preparations of the purified protein. The consensus sequence obtained is as follows:

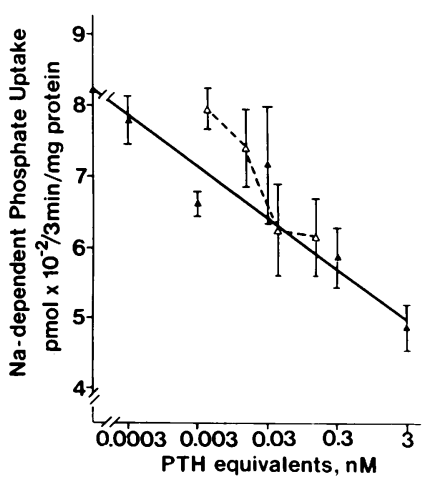

Figure 2. Inhibition of sodium-dependent phosphate uptake in OK cells by PTHlike protein and PTH. Cells were incubated with $\mathrm{bPTH}(1$ 34) (ム) or PTH-like protein $(\Delta)$; cultures were adjusted to an equal volume of gel eluate, using eluate from a gel lane with no sample. The activity of PTH-like protein was determined in the renal adenylate cyclase assay. The Na-independent uptake of phosphate was $105 \pm 24 \mathrm{pmol} / 3 \mathrm{~min}$ per $\mathrm{mg}$ protein and was unaffected by the PTH-like protein. Results are the means \pm SEM of four wells. The experiment was performed three times with similar results.
Cycle num-

$\begin{array}{llllllllllllll}\operatorname{ber} & 1 & 2 & 3 & 4 & 5 & 6 & 7 & 8 & 9 & 10 & 11 & 12 & 13\end{array}$

PTH-like

Protein Ala-Val-Ser--X---X--Gln-Leu-Leu--X---X--Lys--X--Lys

Human

PTH Ser-Val-Ser-Glu-Ile-Gln-Leu-Met-His-Asn-Leu-Gly-Lys

The yield at cycle 2 (valine) was in the range of 5 to 8 pmol for each sequencer run. An $X$ denotes an unknown assignment for the position due to high background in the sequence analyses. In one degradation alanine was observed at position 5 and proline at position 9, but these assignments could not be confirmed in the subsequent sequence analysis. The sequence of human PTH (15) is shown for comparison. Five amino acid identities between the two peptides were noted in the first 13 positions.

\section{Discussion}

The predominant form of a PTH-like protein purified from conditioned culture medium of a human renal carcinoma cell line has a molecular weight of $\sim 6,000$ by gel electrophoresis. Evidence for purity of this form includes the finding of a single stained band corresponding to the peak of activity, and the finding of a single amino-terminal peptide sequence in two independent preparations. Insufficient quantities of the purified material were available to allow determination of mass, but based on estimates from protein staining, the potency for stimulation of cAMP in osteosarcoma cells is similar to that of PTH. However, the PTH-like protein is about 20 -fold less potent (relative to PTH) in a renal adenylate cyclase assay than in the osteosarcoma cell bioassay. The relative insensitivity of renal adenylate cyclase to the PTH-like protein has been reported previously (10). Although no evidence was found for preferential degradation of the PTH-like protein under adenylate cyclase assay conditions (10), differential degradation of the protein, heterogeneity of PTH receptors, and differences in receptor-adenylate cyclase coupling remain as possible explanations for this finding.

The PTH receptor identified by radioligand binding studies in canine renal plasma membranes is coupled to adenylate cyclase (11). The present finding that a PTH-like protein shares this site thus provides direct support for the view that activation of renal adenylate cyclase by this protein results from occupation of the PTH receptor. This confirms previous inferences based upon inhibition of adenylate cyclase activation by competitive antagonists of PTH $(4,5)$. Further evidence that the PTH-like protein, as well as PTH, binds to adenylate cyclase-coupled receptors is provided by the inhibition of binding by $\mathrm{Gpp}(\mathrm{NH}) \mathrm{p}$. The sensitivity of PTH binding to guanine nucleotides probably results from an interaction of the PTH receptor with a guanine nucleotide binding component of the adenylate cyclase complex (11).

The purified PTH-like protein, like PTH itself, produced dose-dependent inhibition of sodium-coupled phosphate transport in OK cells. This transporter (14) is similar to the apical transporter in mammalian kidney, whose inhibition by PTH produces phosphaturia via a cAMP-dependent mechanism. PTH-induced inhibition of sodium-dependent phosphate uptake in OK cells also appears to be mediated by cAMP 
(16). It is thus likely that the PTH-like protein inhibits phosphate transport by activating adenylate cyclase-coupled PTH receptors. Inhibition of renal phosphate transport in vivo by a partially purified preparation of PTH-like factor has previously been reported (8).

The purified PTH-like protein is also a potent bone-resorbing substance. The potency of conditioned medium of 786-0 cells for stimulation of bone resorption was about five-fold greater than the potency for activation of renal adenylate cyclase (7). The potency of purified PTH-like protein for stimulation of bone resorption is similar. Thus much of the boneresorbing activity secreted by 786- 0 cells may be attributable to the PTH-like protein.

The purification of PTH-like proteins from extracts of human breast carcinoma (17) and from conditioned medium of a human squamous lung carcinoma cell line, $\operatorname{BEN}(18)$, has recently been accomplished. ${ }^{2}$ The amino-terminal sequence of the PTH-like protein from both sources is identical to that reported here $(18,19)$, with additional identities to human PTH at three positions not identified in the present work $\left({ }^{4} \mathrm{Glu},{ }^{9} \mathrm{His}\right.$, and $\left.{ }^{12} \mathrm{Gly}\right)$, for a total of eight identities in the amino-terminal 13 residues. Alanine, identified at the aminoterminus in the PTH-like protein, is present at that position in bovine and rat PTH. It is likely that high-affinity binding of PTH-like protein to the PTH receptor is attributable to its structural similarity to PTH. The substitution of ${ }^{8}$ Leu for ${ }^{8} \mathrm{Met}$ probably accounts for the resistance of PTH-like protein to inactivation under oxidizing conditions (17) (e.g., iodination with chloramine T), as the sensitivity of PTH to oxidation has been attributed to formation of 8-methionine sulfoxide (20).

The PTH-like proteins isolated from BEN cells and breast carcinoma have molecular weights of about 17,000-18,000. Extracts of a human lung carcinoma contain a 7,000-9,000 molecular weight PTH-like protein with an $\mathrm{N}$-terminal sequence identical to that of the larger form (19). This smaller form, as well as the multiple species isolated from 786-0 medium in the present study, could be proteolytic fragments of a larger protein similar or identical to that from BEN cells and breast carcinoma. If so, the finding of bioactive 6,000 and 3,400 molecular weight forms may indicate that, as with PTH, the biologic activity of PTH-like proteins resides in a relatively restricted (presumably amino-terminal) domain.

Further studies are needed to establish the role, if any, for PTH-like proteins and for bone-resorbing growth factors and cytokines in the syndrome associated with hypercalcemia in malignancy. However, the similarities between PTH-like proteins and PTH itself, both in amino-terminal sequence and in biological activity, raise the possibility that PTH-like proteins could be responsible for the syndrome, including excessive bone resorption, increased nephrogenous CAMP, and phosphaturia. It should now be possible to clarify the normal and pathophysiological roles of the PTH-like proteins.

\section{Acknowledgments}

We thank Dinh Diep and Shirley Snerling for skilled technical assistance; Claude D. Arnaud and Richard D. Williams for encouragement

2. After acceptance of this manuscript the complete amino acid sequence deduced from molecular cloning of the PTH-like protein from human lung carcinoma was reported (21). The deduced sequence contains the amino acid sequence reported in the present study. and advice; Carl Bennett and Pau Yuan for help with sequencing; and T. John Martin and Andrew F. Stewart for providing results before publication.

This work was supported by grants PDT-229 from the American Cancer Society, AM-35323, AM-11262, and CA-34738 from the National Institutes of Health and by funds from the Medical Research Service of the Veterans Administration.

\section{References}

1. Case records of the Massachusetts General Hospital. Case 27461. 1941. N. Engl. J. Med. 225:789-791.

2. Benson, R. C. Jr., B. L. Riggs, B. M. Pickard, and C. D. Arnaud. 1974. Radioimmunoassay of parathyroid hormone in hypercalcemic patients with malignant disease. Am. J. Med. 56:821-825.

3. Stewart, A. F., R. Horst, L. J. Deftos, E. C. Cadman, R. Lang, and A. E. Broadus. 1980. Biochemical evaluation of patients with cancer-associated hypercalcemia: evidence for humoral and nonhumoral groups. N. Engl. J. Med. 303:1377-1383.

4. Strewler, G. J., R. D. Williams, and R. A. Nissenson. 1983. Human renal carcinoma cells produce hypercalcemia in the nude mouse and a novel protein recognized by parathyroid hormone receptors. J. Clin. Invest. 71:769-774.

5. Stewart, A. F., K. L. Insogna, D. Goltzman, and A. E. Broadus. 1983. Identification of adenylate cyclase-stimulating activity and cytochemical glucose-6-phosphate dehydrogenase-stimulating activity in extracts of tumors from patients with humoral hypercalcemia of malignancy. Proc. Natl. Acad. Sci. USA. 80:1454-1458.

6. Stewart, A. F., K. L. Insogna, W. J. Burtis, A. Aminiafshar, T. Wu, E. C. Weir, and A. E. Broadus. 1986. Frequency and partial characterization of adenylate cyclase-stimulating activity in tumors associated with humoral hypercalcemia of malignancy. J. Bone Min. Res. 1:267-276.

7. Klein, R. F., G. J. Strewler, S. C. Leung, and R. A. Nissenson. 1987. Parathyroid hormone-like adenylate cyclase-stimulating activity from a human carcinoma is associated with bone-resorbing activity. Endocrinology. 120:504-511.

8. Rabbani, S. A., J. Mitchell, D. R. Roy, R. Kremer, H. P. J. Bennett, and D. Goltzman. 1986. Purification of peptides with parathyroid hormone-like bioactivity from human and rat malignancies associated with hypercalcemia. Endocrinology. 118:1200-1210.

9. DeWald, D. B., L. D. Adams, and J. D. Pearson. 1986. A nonurea electrophoretic gel system for resolution of polypeptides of $M_{r}$ 2000 to $\mathrm{M}_{\mathrm{r}}$ 200,000. Anal. Biochem. 154:502-508.

10. Nissenson, R. A., G. J. Strewler, R. D. Williams, and S. C. Leung. 1985. Activation of the parathyroid hormone receptoradenylate cyclase system in osteosarcoma cells by a human renal carcinoma factor. Cancer Res. 45:5358-5363.

11. Nissenson, R. A., E. Mann, J. Winer, A. P. Teitelbaum, and C. D. Arnaud. 1986. Solubilization of a guanine nucleotide-sensitive parathyroid hormone-receptor complex from canine renal cortex. Endocrinology. 118:932-939.

12. Bringman, T. S., P. B. Lindquist, and R. Derynck. 1987. Different transforming growth factor- $\alpha$ species are derived from a glycosylated and palmitoylated transmembrane precursor. Cell. 48:429440.

13. Stern, P. H., and N. S. Krieger. 1983. Comparison of fetal rat limb bones and neonatal mouse calvaria: effects of parathyroid hormone and 1,25-dihydroxyvitamin $\mathrm{D}_{3}$. Calcif. Tissue Int. 35:172-176.

14. Malmstrom, K., and H. Murer. 1986. Parathyroid hormone inhibits phosphate transport in OK cells but not in LLC-PK 1 and JTC-12.P3 cells. Am. J. Physiol. 251(Cell Physiol. 20):C23-C31.

15. Niall, H. D., R. T. Sauer, J. W. Jacobs, H. T. Keutmann, G. V. Segre, J. L. H. O'Riordan, and J. T. Potts, Jr. 1974. The amino-acid sequence of the amino-terminal 37 residues of human parathyroid hormone. Proc. Natl. Acad. Sci. USA. 71:384-388. 
16. Caverzasio, J., R. Rizzoli, and J. P. Bonjour. 1986. Sodium-dependent phosphate transport inhibited by parathyroid hormone and cyclic AMP stimulation in an opossum kidney cell line. J. Biol. Chem. 261:3233-3237.

17. Burtis, W. J., T. Wu, C. Bunch, J. J. Wysolmerski, K. L. Insogna, E. C. Weir, A. E. Broadus, and A. F. Stewart. 1987. Identification of a novel 17,000-Dalton parathyroid hormone-like adenylate cyclase-stimulating protein from a tumor associated with humoral hypercalcemia of malignancy. J. Biol. Chem. 262:7151-7156.

18. Moseley J. M., M. Kubota, H. D. Diefenbach-Jagger, R. E. H. Wettenhall, B. E. Kemp, L. J. Suva, C. P. Rodda, P. R. Ebeliong, P. J. Hudson, J. D. Zajac, and T. J. Martin. 1987. Parathyroid hormone-related protein purified from a human lung carcinoma cell line. Proc. Natl. Acad. Sci. USA. 84:5048-5052.
19. Stewart, A. F., T. Wu, D. Goumas, W. J. Burtis, and A. E. Broadus. 1987. N-terminal amino acid sequence of two novel tumor-derived adenylate cyclase-stimulating proteins: identification of parathyroid hormone-like and parathyroid hormone-unlike domains. Biochem. Biophys. Res. Commun. 146:672-678.

20. Frelinger, A. L. III, and J. E. Zull. 1984. Oxidized forms of parathyroid hormone with biological activity. J. Biol. Chem. 259:5507-5513.

21. Suva L. J., G. A. Winslow, R. E. H. Wettenhall, R. G. Hammonds, J. M. Moseley, H. Diefenbach-Jagger, C. P. Rodda, B. E. Kemp, H. Rodriguez, E. Y. Chen, P. J. Hudson, T. J. Martin, and W. I. Wood. 1987. A parathyroid hormone-related protein implicated in malignant hypercalcemia: cloning and expression. Science (Wash. DC). 237:893-896. 